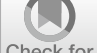

Check for

updates

Cite as

Nano-Micro Lett.

(2021) 13:48

Received: 16 September 2020

Accepted: 19 November 2020

Published online: 4 January 2021

(C) The Author(s) 2021

\section{Band Engineering and Morphology Control of Oxygen-Incorporated Graphitic Carbon Nitride Porous Nanosheets for Highly Efficient Photocatalytic Hydrogen Evolution}

\author{
Yunyan $\mathrm{Wu}^{1,2}$, Pan Xiong ${ }^{1}$, Jianchun $\mathrm{Wu}^{2,3}$, Zengliang Huang ${ }^{2}$, Jingwen $\mathrm{Sun}^{1}$, \\ Qinqin Liu $^{2}$, Xiaonong Cheng ${ }^{2}$, Juan Yang ${ }^{1,2} \bowtie$, Junwu Zhu ${ }^{1 凶}$, Yazhou Zhou ${ }^{2}$
}

\title{
HIGHLIGHTS
}

- The multiple thermal treatments strategy is proposed for preparing the hollow oxygen-incorporated g- $\mathrm{C}_{3} \mathrm{~N}_{4}$ nanosheets $(\mathrm{OCN})$.

- Oxygen-adsorption creates a lot of defects to the formation of hollow and monolayered structure, while oxygen-doping reduces the band gap significantly.

- OCN exhibits stable and high photocatalytic hydrogen evolution with increased surface area, enhanced charge transport, and reduced band gap.

ABSTRACT Graphitic carbon nitride $\left(\mathrm{g}-\mathrm{C}_{3} \mathrm{~N}_{4}\right)$-based photocatalysts have shown great potential in the splitting of water. However, the intrinsic drawbacks of $\mathrm{g}-\mathrm{C}_{3} \mathrm{~N}_{4}$, such as low surface area, poor diffusion, and charge separation efficiency, remain as the bottleneck to achieve highly efficient hydrogen evolution. Here, a hollow oxygen-incorporated $\mathrm{g}-\mathrm{C}_{3} \mathrm{~N}_{4}$ nanosheet (OCN) with an improved surface area of $148.5 \mathrm{~m}^{2} \mathrm{~g}^{-1}$ is fabricated by the multiple thermal treatments under the $\mathrm{N}_{2} / \mathrm{O}_{2}$ atmosphere, wherein the $\mathrm{C}-\mathrm{O}$ bonds are formed through two ways of physical adsorption and doping. The physical characterization and theoretical calculation indicate that the $\mathrm{O}$-adsorption can promote the generation of defects, leading to the formation of hollow morphology, while the O-doping

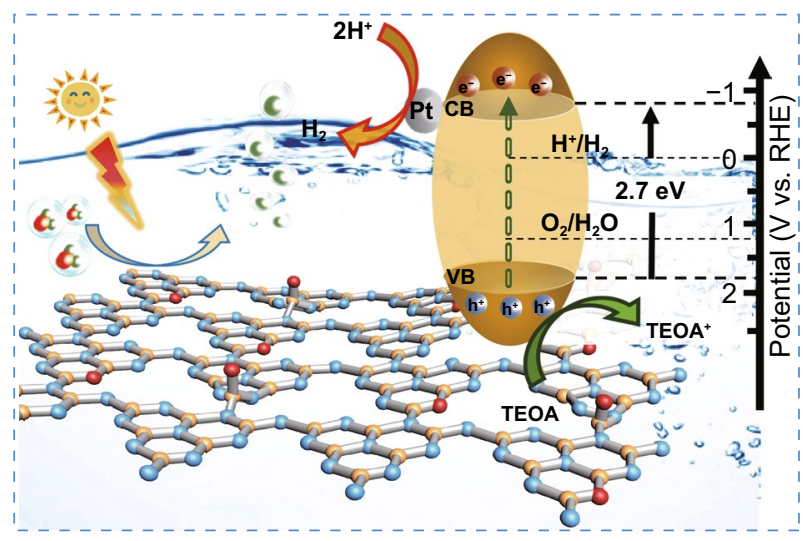
results in reduced band gap of $\mathrm{g}-\mathrm{C}_{3} \mathrm{~N}_{4}$. The optimized OCN shows an excellent photocatalytic hydrogen evolution activity of $3519.6 \mu \mathrm{mol} \mathrm{g}{ }^{-1} \mathrm{~h}^{-1}$ for $\sim 20 \mathrm{~h}$, which is over four times higher than that of g- $\mathrm{C}_{3} \mathrm{~N}_{4}$ $\left(850.1 \mu \mathrm{mol} \mathrm{g} \mathrm{g}^{-1} \mathrm{~h}^{-1}\right)$ and outperforms most of the reported $\mathrm{g}-\mathrm{C}_{3} \mathrm{~N}_{4}$ catalysts.

KEYWORDS Graphitic carbon nitride nanosheet; Hollow morphology; Oxygen incorporating; Multiple thermal treatment; Photocatalytic hydrogen evolution

Y. Wu and P. Xiong have contributed equally to this work.

$₫$ Juan Yang, yangjuan6347@mail.ujs.edu.cn; Junwu Zhu, zhujw@njust.edu.cn; Yazhou Zhou, yazhou@ujs.edu.cn

1 Key Laboratory for Soft Chemistry and Functional Materials, Ministry of Education, Nanjing University of Science and Technology, Nanjing 210094, People's Republic of China

2 School of Materials Science and Engineering, Jiangsu University, Zhenjiang 212013, People's Republic of China

3 Institute of Nuclear Science and Technology, Sichuan University, Chengdu 610064, People's Republic of China 


\section{Introduction}

Due to energy and environmental issues, photocatalysis has attracted intensive interests, as it provides a green and potential route for the wide applications in environmental remediation, energy production, and chemical synthesis [1,2]. During the past several years, various inorganic semiconductors have been developed as photocatalysts for the splitting of water into hydrogen gas under visible light [3,4]. Graphite-like carbon nitride $\left(\mathrm{g}-\mathrm{C}_{3} \mathrm{~N}_{4}\right)$ is not only one of the superior photocatalysts, but also can be used to construct excellent catalysts as substrates owing to high chemical and thermal stability, simple synthesis process, visible-light response, as well as environmentally friendly [5-7]. However, the quality of $g-\mathrm{C}_{3} \mathrm{~N}_{4}$ including the thickness, surface area, electronic structure, etc., still needs to be significantly improved to meet the requirement of applications [8,9] and the morphology design and heteroatom-doping are typical approaches [10-12].

Researches have shown that heteroatom such as nitrogen $(\mathrm{N})$, oxygen $(\mathrm{O})$, sulfur $(\mathrm{S})$, phosphorus $(\mathrm{P})$ dopants play a vital role in promoting the photocatalytic activity of $\mathrm{g}_{-} \mathrm{C}_{3} \mathrm{~N}_{4}$ through broader light-responsive range, higher light utilization efficiency owing to the reduced band gap [13, 14]. For instance, Li et al. [15] found that P-doping could significantly improve the electronic conductivity of g- $\mathrm{C}_{3} \mathrm{~N}_{4}$, leading to the inhibition of recovering of photoseparated charges and holes under visible-light irradiation. Liu et al. [16] proved that the $\mathrm{S}$ dopants could donate valence electrons to covalent $\mathrm{C}$ atoms, resulting in the narrow band gap and improved photo-reactivity of $\mathrm{g}-\mathrm{C}_{3} \mathrm{~N}_{4}$. Unfortunately, it has been convinced that these heteroatom dopants can be easily removed, leading to the poor stability of photocatalytic performance $[17,18]$. O, a typical abundant element, has been used to improve the photocatalytic performance of $\mathrm{g}-\mathrm{C}_{3} \mathrm{~N}_{4}$ through the modification of electronic structures and morphology of $g-\mathrm{C}_{3} \mathrm{~N}_{4}$. For example, Rodrigues et al. prepared $\mathrm{O}-\mathrm{g}-\mathrm{C}_{3} \mathrm{~N}_{4}$ monolayers by the pyrolysis of melamine under the air atmosphere [19]. Niu et al. [20] utilized a 5 min thermal treatment under the well-ventilated air space to prepare porous $\mathrm{O}-\mathrm{g}$ $\mathrm{C}_{3} \mathrm{~N}_{4}$. Compared with bulk g- $\mathrm{C}_{3} \mathrm{~N}_{4}$, the photocatalytic performance of $\mathrm{O}-\mathrm{g}-\mathrm{C}_{3} \mathrm{~N}_{4}$ was enhanced due to the change in band gaps and improved surface areas [21]. Therefore,
O-modified $\mathrm{g}-\mathrm{C}_{3} \mathrm{~N}_{4}$ is a promising approach to further improve the quality of $\mathrm{g}-\mathrm{C}_{3} \mathrm{~N}_{4}$.

In this paper, we demonstrate a novel approach to prepare the hollow $\mathrm{O}$-incorporated $\mathrm{g}-\mathrm{C}_{3} \mathrm{~N}_{4}$ nanosheets (OCN) using the multiple thermal treatments under the $\mathrm{N}_{2} / \mathrm{O}_{2}$ atmosphere. After repeating thermal treatments for three times, the OCN monolayers with uniform pores $(\sim 25 \mathrm{~nm})$ can be obtained. The surface area was increased to $\left(\sim 148.5 \mathrm{~m}^{2} \mathrm{~g}^{-1}\right)$, which is four times higher than that of bulk $\mathrm{g}-\mathrm{C}_{3} \mathrm{~N}_{4}\left(\sim 23.8 \mathrm{~m}^{2} \mathrm{~g}^{-1}\right)$. The obtained OCN exhibited an excellent photocatalytic performance toward hydrogen evolution reaction including a hydrogen evolution rate of $3519.6 \mu \mathrm{mol} \mathrm{g}^{-1} \mathrm{~h}^{-1}$ for $20 \mathrm{~h}$ and quantum efficiency (QE) of $26.96 \%$ at $400 \mathrm{~nm}$, outperforming the bulk $\mathrm{g}_{-} \mathrm{C}_{3} \mathrm{~N}_{4}$ and most of the reported heteroatom-doping g- $\mathrm{C}_{3} \mathrm{~N}_{4}$ [22-27]. The physical characterizations and theoretical calculations indicated that the O-adsorption contributed to form a hollow structure by defect creation and the O-doping played a crucial role in the reduction of the band gap of $g-\mathrm{C}_{3} \mathrm{~N}_{4}$, leading to the improvement of photocatalytic activity.

\section{Experimental Section}

\subsection{Synthesis of OCN}

The OCN was prepared by the multiple thermal treatments. In detail, a certain amount of urea powder was placed in a porcelain crucible with a lid. The crucible containing urea was heated in the tube furnace at a temperature of $550{ }^{\circ} \mathrm{C}$ for $240 \mathrm{~min}$ with a heating rate of $2{ }^{\circ} \mathrm{C} \mathrm{min}{ }^{-1}$ under the $\mathrm{N}_{2} / \mathrm{O}_{2}$ mixed gas $\left(\mathrm{V} / \mathrm{V}: 4: 1,50 \mathrm{~mL} \mathrm{~min}^{-1}\right)$. The yellow powder was obtained. Then, the yellow powder was retreated for $60 \mathrm{~min}$ with the same condition. The as-prepared product was labeled as OCN-N ( $N$ : the thermal treatment times). Finally, a series of OCN- $N$ catalysts, namely OCN-1, OCN-2, OCN-3, and OCN-4, were obtained. The pure bulk $\mathrm{g}-\mathrm{C}_{3} \mathrm{~N}_{4}$ was prepared with the same procedures of OCN-1 but using melamine under argon atmosphere, which was labeled as MCN.

\subsection{Material Characterizations}

The crystal structure of products was characterized by X-ray powder diffraction (XRD) on Rigaku/MiniFlex600 powder 
X-ray with high-intensity $\mathrm{Cu} \mathrm{K} \alpha$. The surface functional groups and chemical compositions of products were performed by $\mathrm{KBr}$ pellet pressing method on Fourier transform infrared spectroscopy (FT-IR, Nicolet Avatar-330) and X-ray photoelectron spectroscopy (XPS) on ESCALAB250Xi. Al $\mathrm{X}$-ray was used as the excitation source. The morphological structures of the product were measured by the scanning electron microscope (SEM, Hitachi S4800), transmission electron microscope (TEM, JEOL JEM-2100) operated at $200 \mathrm{kV}$ (Cs $0.5 \mathrm{~mm}$, point resolution $1.9 \AA$ ) and atomic force microscopy (AFM, Bruker Multimode 8, Germany). The specific surface areas of samples were measured by $\mathrm{N}_{2}$ adsorption-desorption isotherms on a NOVA300e adsorption instrument at $77 \mathrm{~K}$. Then, the corresponding pore-size distributions were calculated using Barrett-Joyner-Halenda (BJH) method. The optical properties of products were tested by UV-vis diffuse-reflectance spectroscopy (UV2550). Photoluminescence (PL) spectra were measured on a QuantaMaster ${ }^{\mathrm{TM}} 40$ fluorescence spectrophotometer with an incident light of $325 \mathrm{~nm}$. The VB-XPS spectrum was carried out to determine the valence band (VB), then the CB potentials of different photocatalysts were calculated according to the following equations: $E_{\mathrm{CB}}=E_{\mathrm{VB}}-E_{\mathrm{g}}$, where $E_{\mathrm{CB}}, E_{\mathrm{VB}}$, and $E_{\mathrm{g}}$ were the conduction band potential, valence band potential ( $E_{\mathrm{VB}}$ from VB-XPS), band gap ( $E_{\mathrm{g}}$ from UV-vis DRS). Flat band potentials of different samples are obtained by intercepting the tangent of the Mott-Schottky curves. Reactive oxygen species (ROS) including $\mathrm{e}^{-}$and $\mathrm{h}^{+}$from composites solution were identified and quantified with electron spin resonance spectroscopy (ESR, JESFA200).

\subsection{Photocatalytic Activity}

The photocatalytic hydrogen production reaction was measured in an online photocatalytic hydrogen production system (LbSolar-3AG, PerfectLight, Beijing). The photocatalysts $(10 \mathrm{mg})$ were added into $100 \mathrm{~mL}$ aqueous solution containing $90 \mathrm{~mL}$ of water and $10 \mathrm{~mL}$ of triethanolamine (TEOA) [28-30]. Pt (acting as a co-catalyst) was then deposited onto catalysts by in situ photodeposition method [31]. A $3 \mathrm{wt} \%$ (respect to $\mathrm{Pt}$ ) $\mathrm{H}_{2} \mathrm{PtCl}_{6} \cdot 6 \mathrm{H}_{2} \mathrm{O}$ solution was added and degassed, and then irradiated by $300 \mathrm{~W}$ Xenon lamp (PLSSXE 300C (BF), PerfectLight, Beijing) with an optical filter $(\lambda>420 \mathrm{~nm})$. Gas concentration analysis was performed by using an online gas chromatograph (GC D7900P, TCD detector). Apparent quantum efficiency (AQE) was measured under the same photocatalytic reaction conditions with irradiation light through a cutoff filter $(400,420,460$, or $550 \mathrm{~nm})[32,33]$. The AQE was calculated in the Supporting Information (Table S1).

\subsection{Photoelectrochemical Experiments}

Electrochemical impedance spectroscopy (EIS), transient photocurrent, and Mott-Schottky plots were tested on CHI 660E (Chenhua Instrument, Shanghai, China) with a typical three-electrode cell. The electrode contains a working electrode (prepared sample), a counter electrode (platinum foil), and a reference electrode $(\mathrm{Ag} / \mathrm{AgCl})$. Here, $0.2 \mathrm{M}$ sodium sulfate $\left(\mathrm{Na}_{2} \mathrm{SO}_{4}\right)$ aqueous solution $(\mathrm{pH}=\sim 5.8)$ was employed as the electrolyte solution, and a $300 \mathrm{~W}$ Xe lamp equipped with a $420 \mathrm{~nm}$ cutoff filter was utilized as the visible-light source. The working electrode was prepared according to the following procedure: $5 \mathrm{mg}$ of the as-prepared photocatalyst was dispersed into a mixed solution containing ethanol $(250 \mu \mathrm{L})$, ethylene glycol $(250 \mu \mathrm{L})$, and Nafion $(40 \mu \mathrm{L})$. The above solution $(80 \mu \mathrm{L})$ was then dropped onto a precleaned fluorine tin oxide (FTO) glass with an exposed area of $1 \mathrm{~cm}^{2}$. The photocurrent responses of the photocatalysts to light switching on and off were measured with $1.2 \mathrm{~V}$ bias voltage. EIS spectra were recorded in the range from 0.01 to $10^{5} \mathrm{~Hz}$ at an ac voltage of $10 \mathrm{mV}$. Mott-Schottky plots of material were then tested at $500 \mathrm{~Hz}$ frequencies by using the impedance-potential mode.

\subsection{Theoretical Calculation}

The spin-polarized density functional theory (DFT) calculations were carried out by using the Vienna Ab-initio simulation package (VASP) [34]. All the calculations were performed to describe the electron-ion interaction by using a plane-wave basis and a projector augmented wave (PAW) method. The generalized-gradient approximations (GGA) with the standard norm conserving Perdew-Burke-Ernzerhof (PBE) and Heyd-Scuseria-Ernzerhof (HSE06) exchange-correlation functionals were employed to obtain the exchange and correlation energy [35]. The energy cutoff for the plane-wave basis wave functions was $400 \mathrm{eV}$ and the Gaussian smearing width was set as $0.05 \mathrm{eV}$. The Brillouin zone was 
sampled by a Gamma centered $3 \times 3 \times 1$ Monkhorst Pack grid. All atoms were converged to $0.01 \mathrm{eV} \AA^{-1}$. A $3 \times 3 \times 1$ supercell model of monolayer $\mathrm{g}-\mathrm{C}_{3} \mathrm{~N}_{4}$ was first relaxed by $\mathrm{PBE}$ approximations, and then the HSE06 calculations were employed to describe electronic structures of different $\mathrm{g}-\mathrm{C}_{3} \mathrm{~N}_{4}$ samples. Compared with conventional DFT, our calculations could obtain the more exact electronic structures and band gaps by means of HSE06 hybrid density functionals. The calculated $\mathrm{N}-\mathrm{C}$ bond length is consistent with the published values $[35,36]$. The energy balance $(\mathrm{Eb})$ is defined as $: \mathrm{Eb}=E\left(\mathrm{O}-\mathrm{g}-\mathrm{C}_{3} \mathrm{~N}_{4}\right)-\left(E\left(\mathrm{~g}-\mathrm{C}_{3} \mathrm{~N}_{4}\right)+E(\mathrm{O})-n E(\mathrm{~N})\right)$, $\mathrm{n}=0$ (O-adsorption) or 1 (O-doping), where $E(\mathrm{O})$ and $E(\mathrm{~N})$ refer to the total energy of $\mathrm{O}$ and $\mathrm{N}$ species, which is calculated from the isolated $\mathrm{O}_{2}$ and $\mathrm{N}_{2}$ molecule [21, 37].

\section{Results and Discussion}

The OCN material was prepared by the multiple thermal treatments, and the critical concept for synthesis is illustrated in Fig. 1. Under the first thermal treatment by urea in the $\mathrm{N}_{2} / \mathrm{O}_{2}$ atmosphere, $\mathrm{O}$ atoms adsorbed and combined with $\mathrm{g}_{-} \mathrm{C}_{3} \mathrm{~N}_{4}$ (Fig. 1a, b). When the OCN-1 was retreated under the $\mathrm{N}_{2} / \mathrm{O}_{2}$ atmosphere, $\mathrm{O}$ atoms were easy to be doped into the skeleton (Fig. 1c, d). Using the multiple thermal treatments, a series of oxygen-incorporated sheets OCN-2 and OCN-3 can be obtained and tuned. However, excessive treatments may lead to the fragmentation of OCN-4 material. In order to further confirm the exact position of $\mathrm{O}$ atom in OCN, the DFT calculations were employed. The five possible action sites $\left(\mathrm{N}_{1}, \mathrm{C}_{2}, \mathrm{~N}_{3}, \mathrm{C}_{4}, \mathrm{~N}_{5}\right)$ were proposed based on the locations of oxygen atoms (Fig. S1). The HSE06 (a)

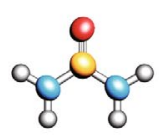

Urea

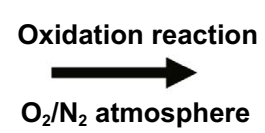

$\mathrm{O}_{2}$ ON OC OO OH (b)

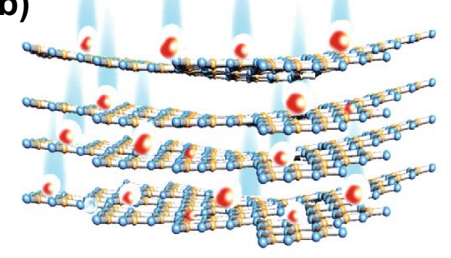

(c)

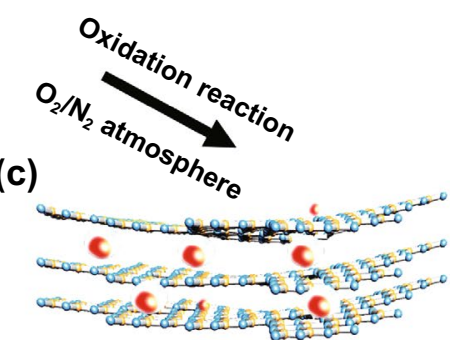

(e)

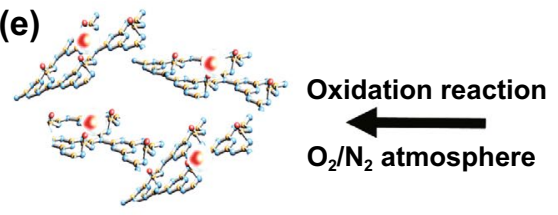

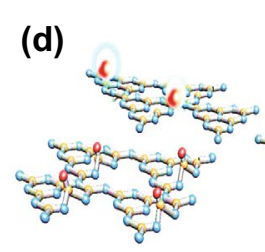
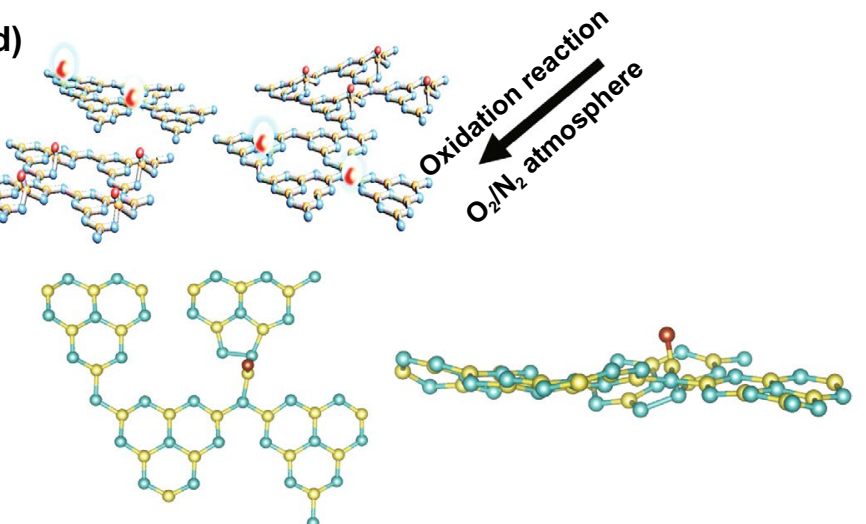

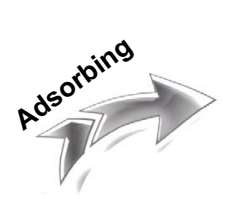

(f)
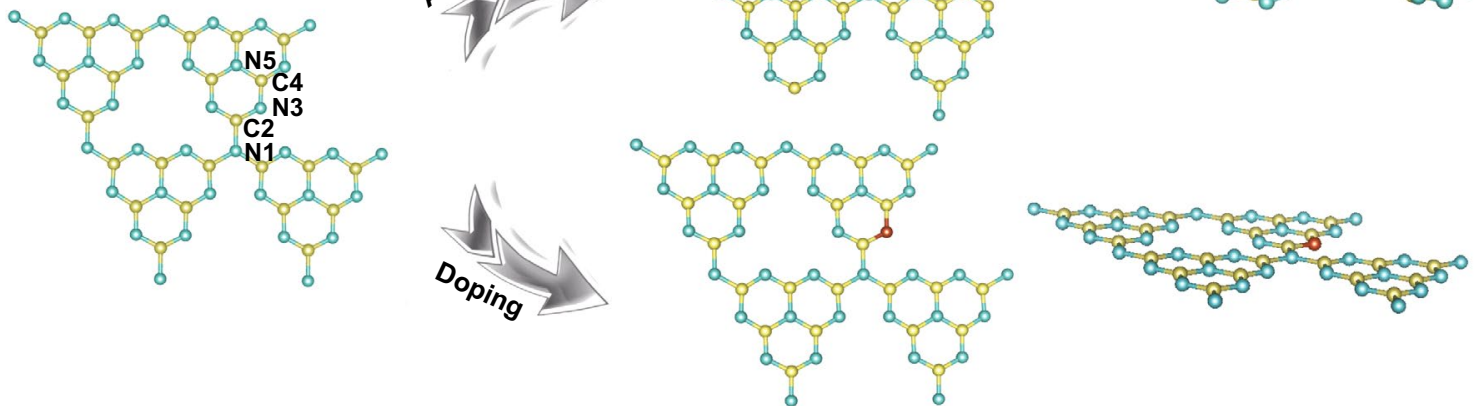

Fig. 1 a-e Synthetic route and $\mathbf{f}$ DFT computational simulation of $\mathrm{OCN}$ which oxygen atoms locate at $\mathrm{C}_{2}$ (adsorbing site) and $\mathrm{N}_{3}($ doping site) with low energy 
calculated results showed that the $\mathrm{O}$ structure with $\mathrm{C}_{2}$ site has a lowest adsorbing energy $(-2.17 \mathrm{eV})$, while the structure with $\mathrm{N}_{3}$ site has a lowest doping energy $(-1.63 \mathrm{eV})$. Thus, it is likely that both O-adsorption and O-doping in $\mathrm{g}-\mathrm{C}_{3} \mathrm{~N}_{4}$ skeleton were existed to construct the $\mathrm{C}-\mathrm{O}$ bond in $\mathrm{OCN}$ during the multiple thermal treatments (Fig. 1f). Different from O-doping, O-adsorption can make $\mathrm{g}-\mathrm{C}_{3} \mathrm{~N}_{4}$ distorted.

The morphologies of a series of OCN were then analyzed by TEM and AFM. The TEM (Fig. 2a) and AFM (Fig. 2d) images displayed the typical sheet-like OCN-1 sheet was measured as $2.28 \mathrm{~nm}$ based on the corresponding height profiles of AFM results, indicating the $\mathrm{OCN}-1$ contained
6-7 layers according to the theoretical interlayer distance of $\mathrm{g}^{-} \mathrm{C}_{3} \mathrm{~N}_{4}(\sim 0.35 \mathrm{~nm})$ [36-39]. After the second thermal treatment, the size and thickness of $\mathrm{g}-\mathrm{C}_{3} \mathrm{~N}_{4}$ sheet $(\mathrm{OCN}-2)$ were decreased to $\sim 1 \mu \mathrm{m}$ and $\sim 0.91 \mathrm{~nm}$, respectively (Fig. $2 \mathrm{~b}, \mathrm{e}$ ), indicating that repeating thermal treatment was helpful to obtain thinner $\mathrm{g}_{-} \mathrm{C}_{3} \mathrm{~N}_{4}$ nanosheets. Further repeating thermal treatment, nearly monolayered OCN-3 nanosheet with $500 \mathrm{~nm}$ size and $0.45 \mathrm{~nm}$ thickness was obtained (Fig. 2c, f). Moreover, the pores with a uniform size of $25 \mathrm{~nm}$ were found on the OCN-3 nanosheets. However, the OCN-4 that was prepared by four-time thermal treatment showed a significantly decreased size $(\sim 160 \mathrm{~nm})$, an increased thickness (a)

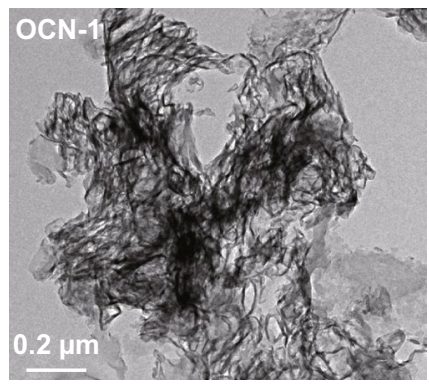

(d)

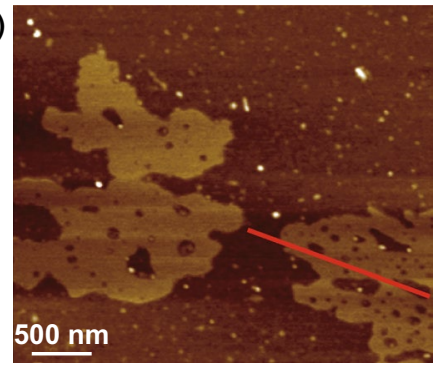

(b)

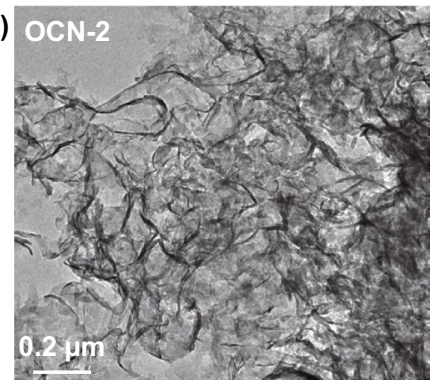

(e)

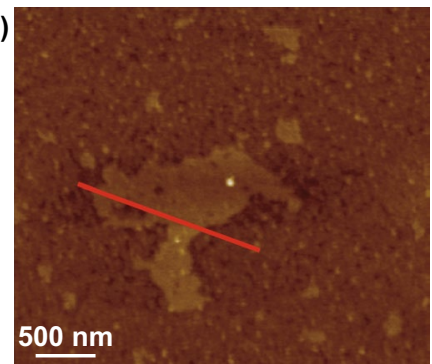

(c)

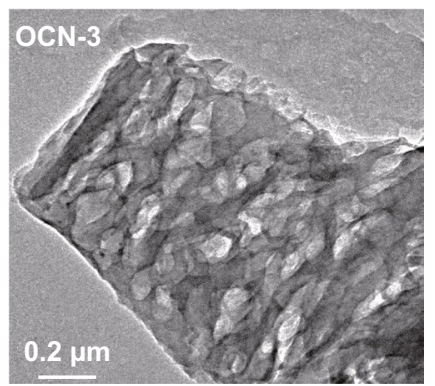

(f)

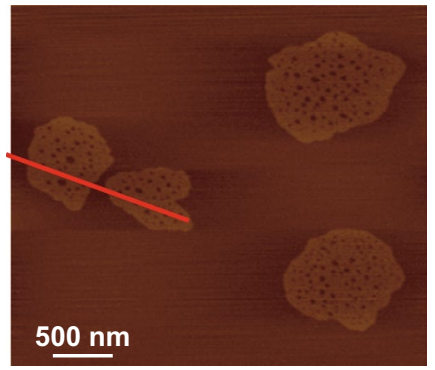

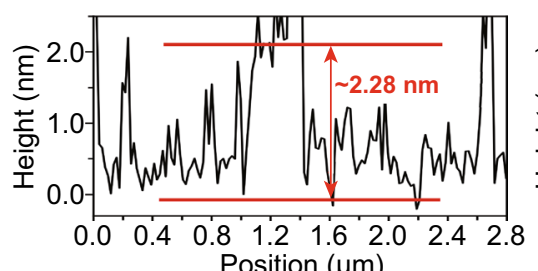
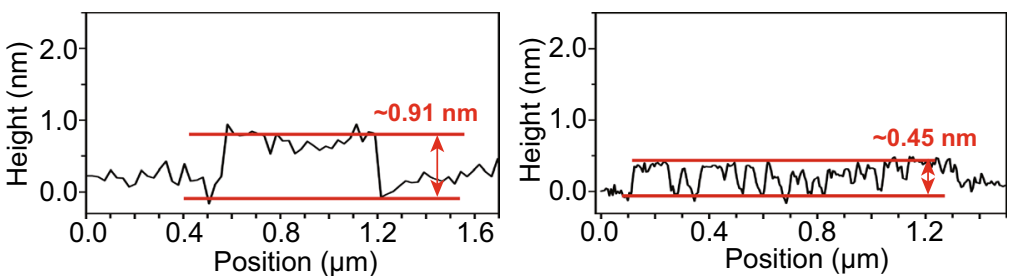

(g)

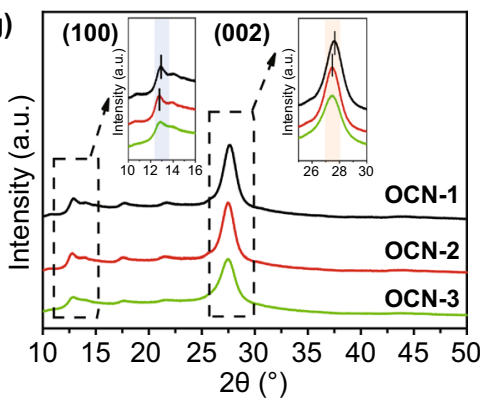

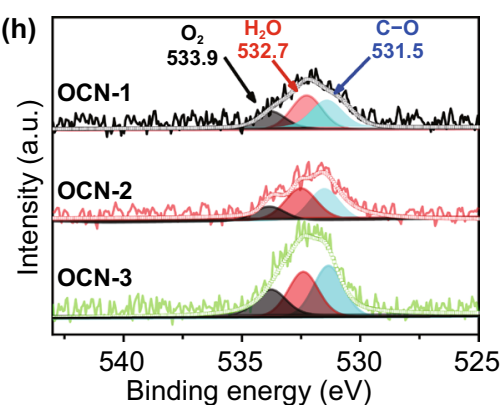

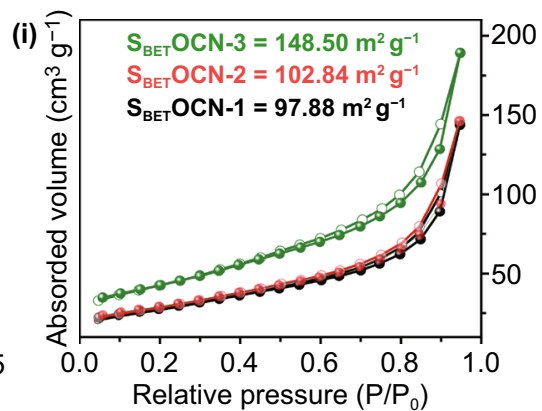

Fig. 2 a-f TEM, AFM images and corresponding height profiles of sample. g-i X-ray diffraction patterns, O 1 s XPS spectra and nitrogen adsorption/desorption isotherms of OCN materials 
$(\sim 2.49 \mathrm{~nm})$ and disappeared pores compared with those of OCN-3 (Fig. S2). As four-time thermal treatments, the obtained $\mathrm{g}-\mathrm{C}_{3} \mathrm{~N}_{4}$ with smaller size tended to aggregate to form the thicker $\mathrm{g}-\mathrm{C}_{3} \mathrm{~N}_{4}$ sheets due to the high surface energy [40]. Thus, the $\mathrm{g}-\mathrm{C}_{3} \mathrm{~N}_{4}$ sheets were torn into smaller fragments with the defects by the multiple thermal treatments and the three-time thermal treatment was the optimized condition for the synthesis of OCN with hollow and monolayered structures. Convinced by DFT results, the introduction of $\mathrm{O}$ can generate defects by distorting, then form $\mathrm{g}-\mathrm{C}_{3} \mathrm{~N}_{4}$ sheets with pores.

As shown in XRD patterns (Fig. $2 \mathrm{~g}$ ), two peaks at $13.0^{\circ}$ and $27.3^{\circ}$ could be detected, which were attributed to the in-plane repeating unites and interlayer-structure stacking of (100) and (002) of $\mathrm{g}^{-} \mathrm{C}_{3} \mathrm{~N}_{4}$, respectively [41, 42]. There were no obvious changes among these OCNs, implying that the multiple thermal treatments did not affect the $\mathrm{g}-\mathrm{C}_{3} \mathrm{~N}_{4}$ phase composition. More importantly, these peaks tended to slightly shift toward a smaller angle, which proved again that the multiple thermal treatments were useful for expanding the interlayer space to obtain the exfoliated $g-\mathrm{C}_{3} \mathrm{~N}_{4}$ sheets with few layers [43]. In the FT-IR spectra of products (Fig. S3a), the sharp band at $\sim 810 \mathrm{~cm}^{-1}$ was the characteristic breathing mode of s-triazine ring. The bands from $\sim 1800$ to $900 \mathrm{~cm}^{-1}$ were the typical stretching vibration modes of $\mathrm{C}=\mathrm{N}$. The broad band between $~ 3000$ and $3600 \mathrm{~cm}^{-1}$ was attributed to $\mathrm{C}-\mathrm{N}$ heterocycles. The FT-IR results were highly consistent with $\mathrm{g}-\mathrm{C}_{3} \mathrm{~N}_{4}$ reported in the literature [44]. Importantly, the $\mathrm{C}-\mathrm{O}$ vibration band could be clearly found at $1090 \mathrm{~cm}^{-1}$ and its intensity was increasing with the repeating thermal treatment, suggesting that O-containing group was successfully formed in the product. Furthermore, no $\mathrm{N}-\mathrm{O}$ band $\left(980 \mathrm{~cm}^{-1}\right)$ was found, indicating that the $\mathrm{N}$ atoms of $\mathrm{g}-\mathrm{C}_{3} \mathrm{~N}_{4}$ nanosheets were not bonded with $\mathrm{O}$ atoms during the thermal treatment which can be evidenced by the oxygen atom site $\left(\mathrm{C}_{2}, \mathrm{~N}_{3}\right)$ from DFT computational structure. XPS survey spectra (Fig. S3b) showed that all products were composited by $\mathrm{C}, \mathrm{N}$, and $\mathrm{O}$ elements. The high-resolution $\mathrm{C} 1 \mathrm{~s}$ spectra exhibited one prominent peak in each product at $287.8 \mathrm{eV}$ (Fig. S3c), which was identified as $\mathrm{sp}^{2}$-bonded $\mathrm{C}$ of $\mathrm{N}=\mathrm{C}-(\mathrm{N})_{2}$. The high-resolution $\mathrm{N}$ $1 \mathrm{~s}$ spectra displayed three peaks at ca. 398.4, 399.9, and $400.9 \mathrm{eV}$ corresponding to $\mathrm{C}=\mathrm{N}-\mathrm{C}, \mathrm{N}(\mathrm{C})_{3}$, and $\mathrm{C}-\mathrm{N}-\mathrm{H}$ groups (Fig. S3d). The XPS results proved again that the typical $\mathrm{g}-\mathrm{C}_{3} \mathrm{~N}_{4}$ structure could be maintained during the multiple thermal treatments [37]. The $\mathrm{C}-\mathrm{O}$ bond, adsorbed
$\mathrm{H}_{2} \mathrm{O}$, and adsorbed $\mathrm{O}_{2}$ could be found in high-resolution $\mathrm{O}$ $1 \mathrm{~s}$ (Fig. 2h) XPS spectra of OCN products [45]. After the multiple thermal treatments, the $\mathrm{O}$ content was increased from 0.84 at $\%$ for OCN-1 to 2.07 at\% for OCN-4 (Table S2). According to the proportions of different kinds of $\mathrm{O}$ bonds in Table $\mathrm{S} 3$, more $\mathrm{C}-\mathrm{O}$ bonds might be formed in the $\mathrm{OCN}$ nanosheet with the increasing thermal treatments. In addition, the change in $\mathrm{O}$ content was also reflected from the color of the products that were changed from yellow to light khaki with the increase in O content (Fig. S4). Overall, the current data can prove that it is a promising strategy by using a multiple thermal treatment method for the preparation of OCN with controllable O content.

The porous structure was studied by $\mathrm{N}_{2}$ adsorption/desorption measurement. As shown in Fig. S5, all the products displayed similar isotherm curves with a typical IV hysteresis loop. The corresponding pore-size distributions were calculated using the Barrett-Joyner-Halenda (BJH) method (Fig. S6), which showed that the products contained a broad pore-size distribution from mesopores to macropores. The OCN-3 exhibited the highest surface area of $148.50 \mathrm{~m}^{2} \mathrm{~g}^{-1}$ in Fig. 2i, compared with that of OCN-1 $\left(97.88 \mathrm{~m}^{2} \mathrm{~g}^{-1}\right)$, OCN-2 (102.84 $\left.\mathrm{m}^{2} \mathrm{~g}^{-1}\right)$, OCN-4 $\left(111.92 \mathrm{~m}^{2} \mathrm{~g}^{-1}\right)$. Compared with pure bulk $\mathrm{g}_{-} \mathrm{C}_{3} \mathrm{~N}_{4}\left(\mathrm{MCN}, 23.84 \mathrm{~m}^{2} \mathrm{~g}^{-1}\right.$ ) in Fig. S7, a highly porous structure of $\mathrm{OCN}-3$ monolayer structure with one atomic thickness $(0.45 \mathrm{~nm})$ could be beneficial to increase the surface area with abundant active sites for photocatalytic reaction $[37,45,46]$.

The photocatalytic hydrogen evolution activities of different samples were investigated. After $5 \mathrm{~h}$ full arc light irradiation (Fig. 3a), the total amount of produced $\mathrm{H}_{2}$ for OCN-1, OCN-2, OCN-3, and OCN-4 materials was 309.5, 410.2, 703.5, and 568.5 $\mu \mathrm{mol}$, respectively. The photocatalytic hydrogen evolution activity of OCN catalysts was enhanced with increasing thermal treatment times up to three times. It decreased when the further thermaltreatment process was performed $(\mathrm{OCN}-4)$ due to the morphology damages and nanosheet aggregates. Among all catalysts, OCN-3 exhibited the best activity toward hydrogen evolution including the highest hydrogen produced rate of $14,069.8 \mu \mathrm{mol} \mathrm{g}^{-1} \mathrm{~h}^{-1}$ (Fig. 3b), which was much higher than that of OCN-1 $\left(6189.6 \mu \mathrm{mol} \mathrm{g}{ }^{-1} \mathrm{~h}^{-1}\right)$, OCN-2 (8203.3 $\left.\mu \mathrm{mol} \mathrm{g}^{-1} \mathrm{~h}^{-1}\right)$, OCN-4 $\left(11,372.3 \mu \mathrm{mol} \mathrm{g}{ }^{-1} \mathrm{~h}^{-1}\right)$, and MCN $\left(3520.6 \mu \mathrm{mol} \mathrm{g}^{-1} \mathrm{~h}^{-1}\right)$. Even under the visible-light irradiation $(\lambda \geq 420 \mathrm{~nm}$, Fig. 3c), the hydrogen evolution activity of the OCN-3 sample was also most 

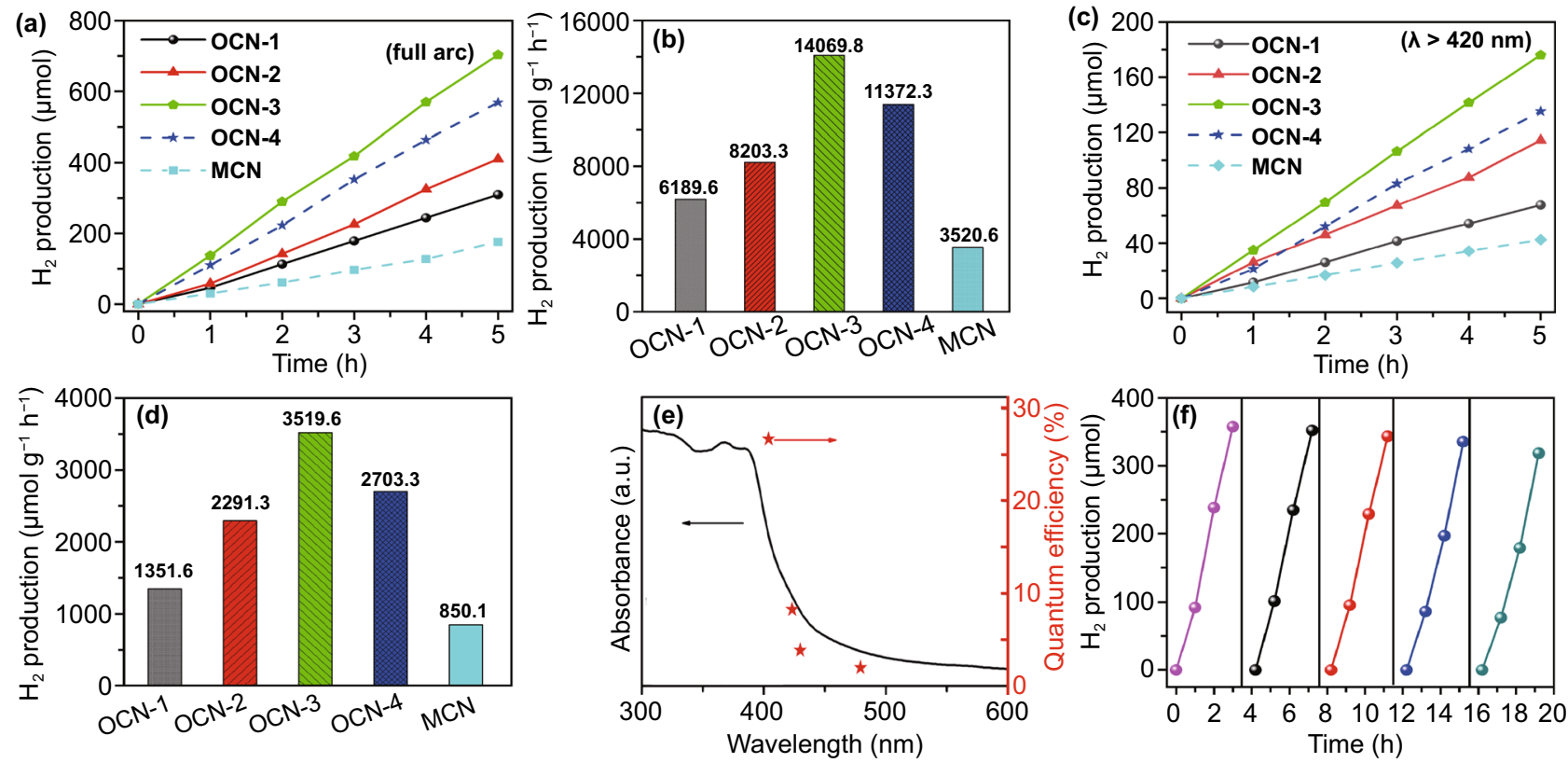

Fig. 3 a-d Time course of hydrogen evolution and comparison of hydrogen evolution rates over $5 \mathrm{~h}$ for different simples under a $300 \mathrm{~W}$ Xe lamp without an optical filter (full arc, a, b) and with a optical filter $(\lambda>420 \mathrm{~nm}, \mathbf{c}, \mathbf{d}), \mathbf{e - f}$ QE against light wavelength and cyclic photocatalytic $\mathrm{H}_{2}$ evolution curve of $\mathrm{OCN}-3$

active, and the total amount of produced $\mathrm{H}_{2}$ could reach $180 \mu \mathrm{mol}$ for $5 \mathrm{~h}$. The calculated hydrogen evolution rate for OCN-3 was up to $3519.6 \mu \mathrm{mol} \mathrm{g} \mathrm{g}^{-1} \mathrm{~h}^{-1}$ under the visible light, which was about $2.60,1.53,1.30$, and 4.14 times higher than that of OCN-1 $\left(1351.6 \mu \mathrm{mol} \mathrm{g}^{-1} \mathrm{~h}^{-1}\right), \mathrm{OCN}-2$ (2291.3 $\left.\mu \mathrm{mol} \mathrm{g}^{-1} \mathrm{~h}^{-1}\right)$, OCN-4 $\left(2703.3 \mu \mathrm{mol} \mathrm{g}^{-1} \mathrm{~h}^{-1}\right)$, and $\operatorname{MCN}\left(850.1 \mu \mathrm{mol} \mathrm{g}^{-1} \mathrm{~h}^{-1}\right)$ (Fig. 3d).

To further obtain the reaction proceeds of OCN-3 through light absorption, we explored the relationship between the QE of hydrogen evolution and wavelength of incident light. It can be seen that the QE decreased with increasing wavelengths which matched well with the height variation of absorption peaks in the optical spectra. Therefore, the OCN-3 catalyst had a peak external QE of $26.96 \%$ at $400 \mathrm{~nm}$ and $4.28 \%$ at $420 \mathrm{~nm}$ (Fig. 3e), which outperformed in the g- $\mathrm{C}_{3} \mathrm{~N}_{4}$-based catalysts reported in the literature (Table S4), including NiMo/g- $\mathrm{C}_{3} \mathrm{~N}_{4}, \mathrm{PDA} @ \mathrm{~g}-\mathrm{C}_{3} \mathrm{~N}_{4}, \mathrm{Ni}(\mathrm{OH})_{2} / \mathrm{CdS} / \mathrm{g}-$ $\mathrm{C}_{3} \mathrm{~N}_{4}[9,13,29,39,46]$. The stability of the OCN-3 was tested by cyclic photocatalytic $\mathrm{H}_{2}$ evolution experiments. After five cycles, OCN-3 still exhibited the high photocatalytic activity toward hydrogen evolution reaction and only $10.4 \%$ activity was lost after $20 \mathrm{~h}$ (Fig. 3f). Structural information of OCN-3 after reaction was also assessed via SEM (Fig. S8) and XRD (Fig. S9) technique. Preserved morphology and similar diffraction patterns before and after cyclic test demonstrate the chemical and photophysical stability of catalysts.

In order to explore the function of introducing oxygen atom toward the photophysical property of OCN, Mott-Schottky plots spectra, PL spectra were first tested. The Mott-Schottky plot was utilized to determine flat band potentials of material. All samples exhibit similar linear plots, corresponding to the character of typical n-type semiconductor in Fig. 4a [47-49]. More importantly, the derived flat potentials of OCN-3 are more negative than that of OCN-1, OCN-2, promising the enhanced reduction ability of photogenerated electrons. In Fig. 4b, all the samples exhibited a strong PL peak at $445 \mathrm{~nm}$, in which OCN-3 has the lowest intensity, indicated the electron/hole separation and electron transport were more efficient through OCN-3 compared with other catalysts [50]. As shown in Fig. 4c, the OCN-3 exhibited a higher photocurrent value of 0.35 $\mu \mathrm{A} \mathrm{cm}{ }^{-2}$ than that of OCN-1 $\left(0.14 \mu \mathrm{A} \mathrm{cm}^{-2}\right)$ and OCN-2 $\left(0.26 \mu \mathrm{A} \mathrm{cm}^{-2}\right)$, demonstrating the improvement in photocurrent response of open circuit voltage with the increasing repeat times of thermal treatment. The higher photocurrent revealed that OCN-3 has a better visible-light response and more efficient photoexcited charge separation, which 

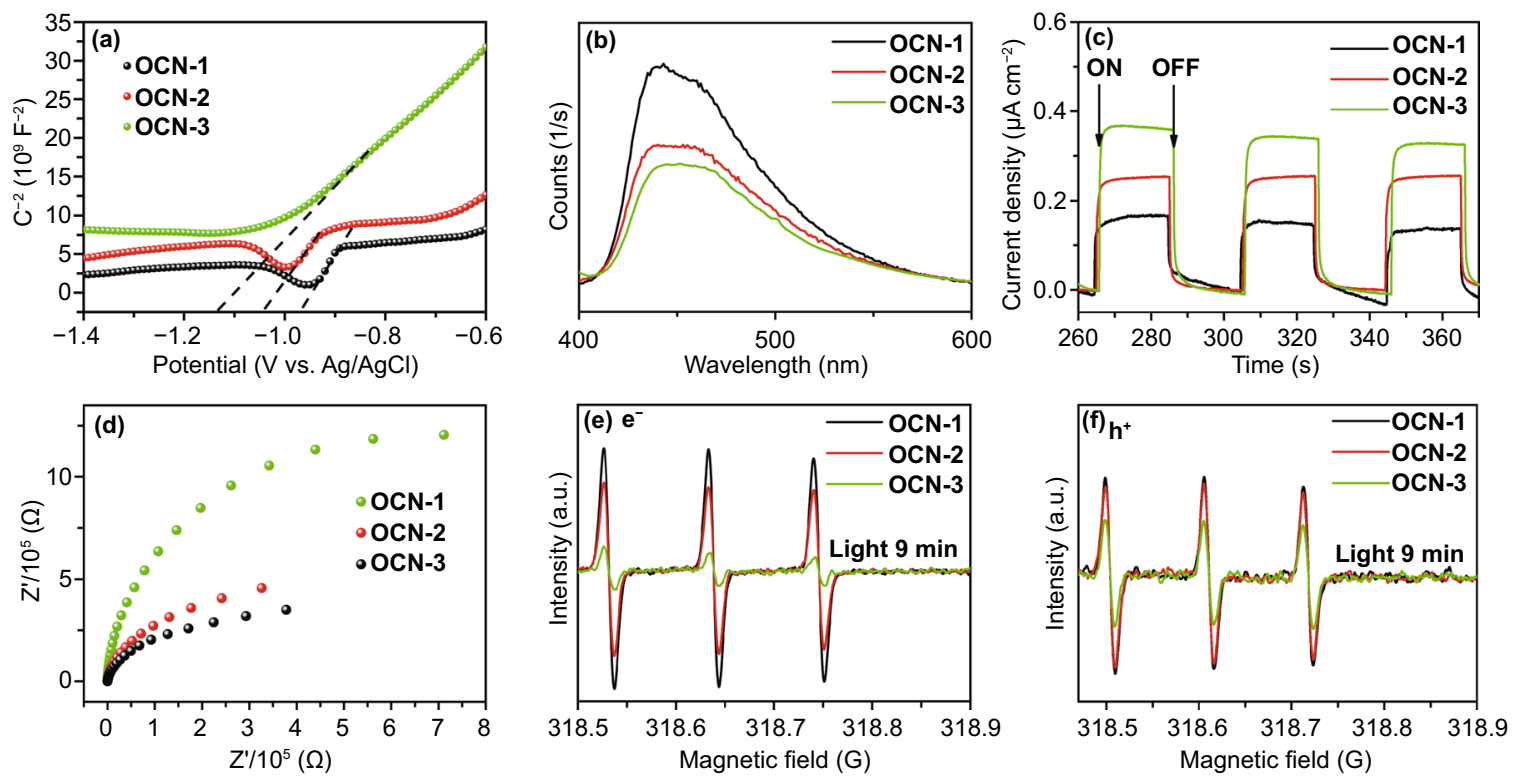

Fig. 4 a Mott-Schottky plots spectra, b steady-state photoluminescence (PL) spectra, $\mathbf{c}$ transient photocurrent responses, $\mathbf{d}$ EIS spectroscopies, e, $\mathbf{f}$ ESR spectra of $\mathrm{e}^{-}$and $\mathrm{h}^{+}$of OCN-1, OCN-2, and OCN-3 under visible-light irradiation for 9 min

was proven again by PL results. Correspondingly, the EIS Nyquist impedance spectra (Fig. 4d) showed that OCN-3 has the smallest electron-transfer resistance. The photoexcited radicals such as electrons and holes from photocatalysts were investigated by the ESR spin-trap technique with TEMPO in Fig. 4e, f. TEMPO with $\mathrm{e}^{-}$or $\mathrm{h}^{+}$can produce an ESR silent molecule and lead to the decrease in the intensity of TEMPO signals [51]. Hence, OCN-3 with weak signals has a large number of $\mathrm{e}^{-}$and $\mathrm{h}^{+}$than those of OCN-1 and OCN-2. In addition, radicals' signal can be found in OCN-3 solution under visible-light irradiation (Fig. S10), decreasing with longer irradiated time. Therefore, the efficient separation of $\mathrm{e}^{-} / \mathrm{h}^{+}$, the high resistance of recombination of $\mathrm{e}^{-} / \mathrm{h}^{+}$, the excellent light harvest make OCN-3 active in photocatalytic hydrogen evolution reaction.

In order to explore the function of introducing oxygen atom, HSE calculation was firstly used to obtain the theoretical density of states (DOS). According to the results of DOS, the band gap of pure $\mathrm{g}-\mathrm{C}_{3} \mathrm{~N}_{4}$ was about $2.58 \mathrm{eV}$ in Fig. 5a which is consistent with reported results [52]. After calculating projected DOS in Fig. S11, the O-adsorption structure only caused a weak effect on band structure from pure $\mathrm{g}^{-} \mathrm{C}_{3} \mathrm{~N}_{4} 2.58 \mathrm{eV}$ to $2.55 \mathrm{eV}$ (Fig. 5b). The band gap of O-doping $\mathrm{g}^{-} \mathrm{C}_{3} \mathrm{~N}_{4}$ decreased from 2.58 to $2.16 \mathrm{eV}$ (Fig. 5c). Such a smaller band gap is befitting for a photocatalyst. Thus, the OCN was more active than pure g- $\mathrm{C}_{3} \mathrm{~N}_{4}$ for splitting water under light irradiation. Beside theoretical calculation, to convince the change in band structure experimentally, UV-vis DRS, VB-XPS were then studied. The UV-vis DRS result exhibited a remarkable red shift and intensity increase in absorption peak of OCN with the multiple thermal treatments (Fig. 5d), indicated the increasing harvest of visible light [53]. The band gaps of OCNs were calculated according to the Kubelka-Munk transformation, which was $2.78,2.76$, and $2.70 \mathrm{eV}$ for OCN-1, OCN-2, and OCN-3, respectively. According to the VB-XPS results, the maximum of the valence band (VB) was located at 2.03, 1.90 , and $1.74 \mathrm{eV}$ for OCN-1, OCN-2, and OCN-3, respectively (Fig. 5e). Thus, the conduction band (CB) was determined to be $-0.97,-1.04$, and $-1.13 \mathrm{~V}$ (vs. $\mathrm{Ag} / \mathrm{AgCl}$, $\mathrm{pH}=7$ ) for OCN-1, OCN-2, OCN-3, respectively, which were converted to $-0.75,-0.86$, and $-0.96 \mathrm{~V}$ versus normal hydrogen electrode (vs. NHE), respectively [49]. The energy band structure can be simulated in Fig. 5f. Indeed, the $\mathrm{CB}$ potential of OCN-3 was smaller than that of other samples and was more negative compared with the $\mathrm{H}^{+} / \mathrm{H}_{2}$ reduction potential (NHE). Thus, the up-shift of conduction band energy can be resulted in a stronger reducing activity of OCN-3, leading to a significant improvement in hydrogen evolution performance. According to the above results, we considered that O-doping could lead $\mathrm{g}-\mathrm{C}_{3} \mathrm{~N}_{4}$ to a significant change in band gap. This function could be ignored 

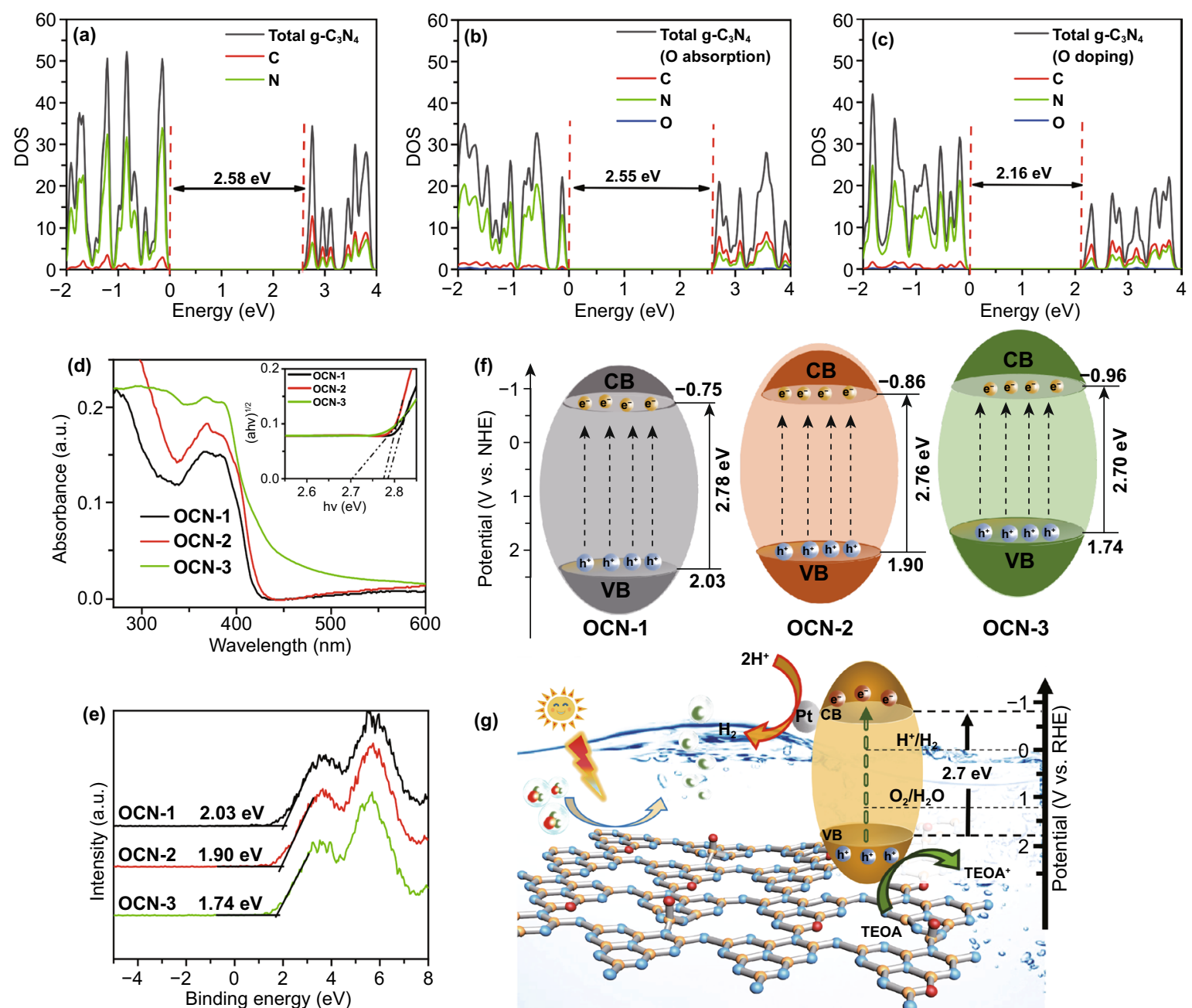

(g)

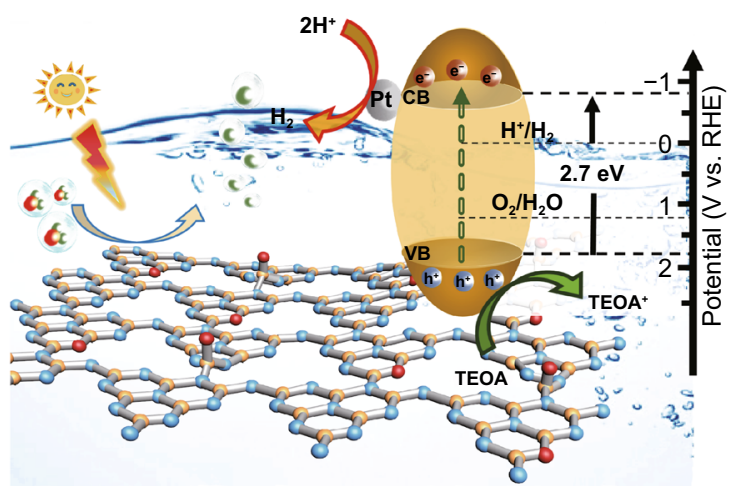

Fig. 5 a Density of state (DOS) of pristine g- $\mathrm{C}_{3} \mathrm{~N}_{4}$, b O-doped $\mathrm{g}_{-} \mathrm{C}_{3} \mathrm{~N}_{4}$, and c O-adsorbed g- $\mathrm{C}_{3} \mathrm{~N}_{4}$. d UV-visible absorbance spectra, e VB-XPS survey, and $\mathbf{f}$ energy level diagrams, $\mathbf{g}$ photocatalytic $\mathrm{H}_{2}$-production mechanism of OCN-1, OCN-2, OCN-3

for O-adsorption. However, the O-adsorption still played an important role in the generation of defects that were contributed to the formation of hollow morphology.

A possible photocatalytic hydrogen production mechanism was proposed, as shown in Fig. $5 \mathrm{~g}$. The $\mathrm{e}^{-}$and $\mathrm{h}^{+}$ pairs were generated when the OCN was irradiated by the visible light. Then, $\mathrm{e}^{-}$in $\mathrm{CB}$ transferred to $\mathrm{Pt}$ for releasing $\mathrm{H}_{2}$ by reducing $\mathrm{H}_{2} \mathrm{O}$, while the generated $\mathrm{h}^{+}$in VB reacted with TEOA to inhibit the recombination of $\mathrm{e}^{-} / \mathrm{h}^{+}$. Since the above steps were intimately associated with the intrinsic characteristics of photocatalyst, such as electronic, surface, and textural structures, an integrated engineering of the above properties would enable a synergetic tuning and optimization to further improve the photocatalytic performance. In our work, we modified the morphology and electronic structure of $\mathrm{g}-\mathrm{C}_{3} \mathrm{~N}_{4}$ by introducing $\mathrm{O}$ using the multiple thermal treatments. On the one hand, the O-adsorption can create more defects in $\mathrm{g}-\mathrm{C}_{3} \mathrm{~N}_{4}$ nanosheets, leading to the formation of a hollow structure that was contributed to the improved surface area. On the other hand, the O-doping can reduce the band gap of $\mathrm{g}-\mathrm{C}_{3} \mathrm{~N}_{4}$. The separation of $\mathrm{e}^{-} / \mathrm{h}^{+}$was promoted through $\mathrm{g}^{-} \mathrm{C}_{3} \mathrm{~N}_{4}$, while the recombination of the generated $\mathrm{e}^{-} / \mathrm{h}^{+}$was inhibited due to the fast transport of electrons over $\mathrm{g}-\mathrm{C}_{3} \mathrm{~N}_{4}$. In doing so, the OCN showed an excellent photocatalytic performance and it holds a promising application such as photocatalysts for hydrogen evolution and substrates for the synthesis of catalysts composites. 


\section{Conclusion}

In summary, we demonstrated a novel approach to synthesize OCN with structure regulation and morphology control by using the multiple thermal treatments under the $\mathrm{N}_{2} / \mathrm{O}_{2}$ atmosphere. The physical characterizations and theorized calculations proved that the multiple thermal treatments played a crucial role in morphology control and structure regulation by introducing $\mathrm{O}$ atoms. There were two kinds of $\mathrm{O}$-incorporated structures. One was O-adsorption that could create a lot of defects to the formation of hollow and monolayered structure. Another was O-doping which can reduce the band gap significantly. Owing to this variation in structure, the optimized OCN-3 showed an excellent visible-light photocatalytic activity toward hydrogen production. The hydrogen evolution activity of OCN-3 was $3519.6 \mu \mathrm{mol} \mathrm{g}^{-1} \mathrm{~h}^{-1}$ for $\sim 20 \mathrm{~h}$, which is over four times higher than that of pure bulk g- $\mathrm{C}_{3} \mathrm{~N}_{4}\left(850.1 \mu \mathrm{mol} \mathrm{g} \mathrm{g}^{-1} \mathrm{~h}^{-1}\right)$. Besides, OCN-3 exhibited a stable photocatalytic activity due to oxygen functions which only $10.4 \%$ activity was lost after $20 \mathrm{~h}$. This work not only demonstrated a powerful strategy to synthesize porous and ultrathin $\mathrm{g}-\mathrm{C}_{3} \mathrm{~N}_{4}$ nanosheet with highly efficient photocatalytic $\mathrm{H}_{2}$ evolution by the function of oxygen, but also paves a new avenue to optimize the electronic, surface, and textural structure for excellent photocatalysts.

Acknowledgments This work was supported by the National Science Foundation of China (51772152, 51702129, 51572114, 51972150, 21908110, and 51902161) and Fundamental Research Funds for the Central Universities (30919011269, 30919011110, and 1191030558). Y.W. thanks the Key University Science Research Project of Jiangsu province (16KJB430009). Y.Z. thanks for the support from the Postdoctoral Science Foundation (2018M630527) and China Scholarship Council (201708320150). J.S. thanks the Natural Science Foundation of Jiangsu Province (BK20190479, 1192261031693). We thank K.C. and L.P. for their helps on TEM, SEM, and PL measurements in Jiangsu University Analysis and Test Center. The authors would like to thank J.D. from the Shiyanjia laboratory (http://www.shiyanjia.com) for the XPS and XRD tests.

Open Access This article is licensed under a Creative Commons Attribution 4.0 International License, which permits use, sharing, adaptation, distribution and reproduction in any medium or format, as long as you give appropriate credit to the original author(s) and the source, provide a link to the Creative Commons licence, and indicate if changes were made. The images or other third party material in this article are included in the article's Creative
Commons licence, unless indicated otherwise in a credit line to the material. If material is not included in the article's Creative Commons licence and your intended use is not permitted by statutory regulation or exceeds the permitted use, you will need to obtain permission directly from the copyright holder. To view a copy of this licence, visit http://creativecommons.org/licenses/by/4.0/.

Supporting information The online version of this article (https ://doi.org/10.1007/s40820-020-00571-6) contains supplementary material, which is available to authorized users.

\section{References}

1. X. Qian, X. Meng, J. Sun, L. Jiang, Y. Wang et al., Saltassisted synthesis of $3 \mathrm{D}$ porous $\mathrm{g}-\mathrm{C}_{3} \mathrm{~N}_{4}$ as a bifunctional photo- and electrocatalyst. ACS Appl. Mater. Interfaces 11, 27226-27232 (2019). https://doi.org/10.1021/acsami.9b08651

2. J. Sun, J. Xu, A. Grafmueller, X. Huang, C. Liedel et al., Self-assembled carbon nitride for photocatalytic hydrogen evolution and degradation of p-nitrophenol. Appl. Catal. B: Environ. 205, 1-10 (2017). https://doi.org/10.1016/j.apcat b.2016.12.030

3. O. Elbanna, M. Zhu, M. Fujitsuka, T. Majima, Black phosphorus sensitized $\mathrm{TiO}_{2}$ mesocrystal photocatalyst for hydrogen evolution with visible and near-infrared light irradiation. ACS Catal. 9, 3618-3626 (2019). https://doi.org/10.1021/acsca tal.8b05081

4. J. Sun, R. Malishev, A. Azoulay, J. Tzadikov, M. Volokh et al., Carbon and nitrogen based nanosheets as fluorescent probes with tunable emission. Small 14, 1800516 (2018). https://doi. org/10.1002/smll.201800516

5. X. Tao, Y. Zhou, K. Xu, Y. Wu, J. Mi et al., Bifunctional material with organic pollutant removing and antimicrobial properties: graphene aerogel decorated with highly dispersed $\mathrm{Ag}$ and $\mathrm{CeO}_{2}$ nanoparticles. ACS Sustain. Chem. Eng. 6, 16907-16919 (2018). https://doi.org/10.1021/acssuschem eng.8b04251

6. J. Ran, J. Qu, H. Zhang, T. Wen, H. Wang et al., 2D metal organic framework nanosheet: a universal platform promoting highly efficient visible-light-induced hydrogen production. Adv. Energy Mater. 9, 1803402 (2019). https://doi. org/10.1002/aenm.201803402

7. X. Wang, K. Maeda, A. Thomas, K. Takanabe, G. Xin et al., A metal-free polymeric photocatalyst for hydrogen production from water under visible light. Nat. Mater. 8, 76-80 (2009). https://doi.org/10.1038/nmat2317

8. X. Qian, J. Ding, J. Zhang, Y. Zhang, Y. Wang et al., Ultrathin molybdenum disulfide/carbon nitride nanosheets with abundant active sites for enhanced hydrogen evolution. Nanoscale 10, 1766-1773 (2018). https://doi.org/10.1039/C7NR07213A

9. X. Han, D. Xu, L. An, C. Hou, Y. Li et al., Ni-Mo nanoparticles as co-catalyst for drastically enhanced photocatalytic hydrogen production activity over $\mathrm{g}-\mathrm{C}_{3} \mathrm{~N}_{4}$. Appl. Catal. B: Environ. 243, 136-144 (2019). https://doi.org/10.1016/j.apcat b.2018.10.003 
10. W. Luo, X. Chen, Z. Wei, D. Liu, W. Yao et al., Three-dimensional network structure assembled by $\mathrm{g}-\mathrm{C}_{3} \mathrm{~N}_{4}$ nanorods for improving visible-light photocatalytic performance. Appl. Catal. B: Environ. 255, 117761 (2019). https://doi. org/10.1016/j.apcatb.2019.117761

11. Y. Shiraishi, S. Kanazawa, Y. Sugano, D. Tsukamoto, H. Sakamoto et al., Highly selective production of hydrogen peroxide on graphitic carbon nitride $\left(\mathrm{g}-\mathrm{C}_{3} \mathrm{~N}_{4}\right)$ photocatalyst activated by visible light. ACS Catal. 4, 774-780 (2014). https://doi.org/10.1021/cs401208c

12. H. Huang, M. Yan, C. Yang, H. He, Q. Jiang et al., Graphene nanoarchitectonics: recent advances in graphene-based electrocatalysts for hydrogen evolution reaction. Adv. Mater. 31, 1903415 (2019). https://doi.org/10.1002/adma.201903415

13. H. Wang, Q. Lin, L. Yin, Y. Yang, Y. Qiu et al., Biomimetic design of hollow flower-like g- $\mathrm{C}_{3} \mathrm{~N}_{4} @$ PDA organic framework nanospheres for realizing an efficient photoreactivity. Small 15, 1900011 (2019). https://doi.org/10.1002/ smll.201900011

14. Q. Xu, B. Zhu, B. Cheng, J. Yu, M. Zhou et al., Photocatalytic $\mathrm{H}_{2}$ evolution on graphdiyne/g- $\mathrm{C}_{3} \mathrm{~N}_{4}$ hybrid nanocomposites. Appl. Catal. B: Environ. 255, 117770 (2019). https://doi. org/10.1016/j.apcatb.2019.117770

15. X. Li, X. Wang, M. Antonietti, Mesoporous $g-\mathrm{C}_{3} \mathrm{~N}_{4}$ nanorods as multifunctional supports of ultrafine metal nanoparticles: hydrogen generation from water and reduction of nitrophenol with tandem catalysis in one step. Chem. Sci. 3, 2170-2174 (2012). https://doi.org/10.1039/C2SC20289A

16. G. Liu, P. Niu, C. Sun, S.C. Smith, Z. Chen et al., Unique electronic structure induced high photoreactivity of sulfur-doped graphitic $\mathrm{C}_{3} \mathrm{~N}_{4}$. J. Am. Chem. Soc. 132, 11642-11648 (2010). https://doi.org/10.1021/ja103798k

17. J. Huang, D. Li, R. Li, Q. Zhang, T. Chen et al., An efficient metal-free phosphorus and oxygen co-doped $g-\mathrm{C}_{3} \mathrm{~N}_{4}$ photocatalyst with enhanced visible light photocatalytic activity for the degradation of fluoroquinolone antibiotics. Chem. Eng. J. 374, 242-253 (2019). https://doi.org/10.1016/j.cej.2019.05.175

18. Y. Kang, Y. Yang, L. Yin, X. Kang, G. Liu et al., An amorphous carbon nitride photocatalyst with greatly extended visible-light-responsive range for photocatalytic hydrogen generation. Adv. Mater. 27, 4572-4577 (2015). https://doi. org/10.1002/adma.201501939

19. X. She, J. Wu, H. Xu, J. Zhong, Y. Wang et al., High efficiency photocatalytic water splitting using $2 \mathrm{D} \alpha-\mathrm{Fe}_{2} \mathrm{O}_{3} / g-\mathrm{C}_{3} \mathrm{~N}_{4}$ Z-scheme catalysts. Adv. Energy Mater. 7, 1700025 (2017). https://doi.org/10.1002/aenm.201700025

20. P. Niu, M. Qiao, Y. Li, L. Huang, T. Zhai, Distinctive defects engineering in graphitic carbon nitride for greatly extended visible light photocatalytic hydrogen evolution. Nano Energy 44, 73-81 (2018). https://doi.org/10.1016/j.nanoe n.2017.11.059

21. J. Ran, T.Y. Ma, G. Gao, X. Du, S. Qiao, Porous P-doped graphitic carbon nitride nanosheets for synergistically enhanced visible-light photocatalytic $\mathrm{H}_{2}$ production. Energy Environ. Sci. 8, 3708-3717 (2015). https://doi.org/10.1039/C5EE0 2650D
22. J. Ran, W. Guo, H. Wang, B. Zhu, J. Yu et al., Metal-free 2D/2D phosphorene/g- $\mathrm{C}_{3} \mathrm{~N}_{4}$ van der waals heterojunction for highly enhanced visible-light photocatalytic $\mathrm{H}_{2}$ production. Adv. Mater. 30, 1800128 (2018). https://doi.org/10.1002/ adma.201800128

23. Y. Zhang, T. Mori, J. Ye, M. Antonietti, Phosphorus-doped carbon nitride solid: enhanced electrical conductivity and photocurrent generation. J. Am. Chem. Soc. 132, 6294-6295 (2010). https://doi.org/10.1021/ja101749y

24. F. Yang, D. Liu, Y. Li, L. Cheng, J. Ye, Salt-template-assisted construction of honeycomb-like structured $\mathrm{g}-\mathrm{C}_{3} \mathrm{~N}_{4}$ with tunable band structure for enhanced photocatalytic $\mathrm{H}_{2}$ production. Appl. Catal. B: Environ. 240, 64-71 (2019). https://doi. org/10.1016/j.apcatb.2018.08.072

25. B. Wulan, S. Yi, S. Li, Y. Duan, J. Yan et al., Amorphous nickel pyrophosphate modified graphitic carbon nitride: an efficient photocatalyst for hydrogen generation from water splitting. Appl. Catal. B: Environ. 231, 43-50 (2018). https:// doi.org/10.1016/j.apcatb.2018.02.045

26. Y. Zhu, T. Ren, Z. Yuan, Mesoporous phosphorus-doped g- $\mathrm{C}_{3} \mathrm{~N}_{4}$ nanostructured flowers with superior photocatalytic hydrogen evolution performance. ACS Appl. Mater. Interfaces 7, 16850-16856 (2015). https://doi.org/10.1021/acsami.5b049 47

27. X. She, J. Wu, J. Zhong, H. Xu, Y. Yang et al., Oxygenated monolayer carbon nitride for excellent photocatalytic hydrogen evolution and external quantum efficiency. Nano Energy 27, 138-146 (2016). https://doi.org/10.1016/j.nanoen.2016.06.042

28. H. Yu, R. Shi, Y. Zhao, T. Bian, Y. Zhao et al., Alkali-assisted synthesis of nitrogen deficient graphitic carbon nitride with tunable band structures for efficient visible-light-driven hydrogen evolution. Adv. Mater. 29, 1605148 (2017). https://doi. org/10.1002/adma.201605148

29. Y. Zeng, X. Liu, C. Liu, L. Wang, Y. Xia et al., Scalable onestep production of porous oxygen-doped $\mathrm{g}-\mathrm{C}_{3} \mathrm{~N}_{4}$ nanorods with effective electron separation for excellent visible-light photocatalytic activity. Appl. Catal. B: Environ. 224, 1-9 (2018). https://doi.org/10.1016/j.apcatb.2017.10.042

30. Y. Wu, Y. Zhou, H. Xu, Q. Liu, Y. Li et al., Highly active, superstable, and biocompatible $\mathrm{Ag} /$ polydopamine/g- $\mathrm{C}_{3} \mathrm{~N}_{4}$ bactericidal photocatalyst: synthesis, characterization, and mechanism. ACS Sustain. Chem. Eng. 6, 14082-14094 (2018). https ://doi.org/10.1021/acssuschemeng.8b02620

31. Y. Kang, Y. Yang, L. Yin, X. Kang, L. Wang et al., Selective breaking of hydrogen bonds of layered carbon nitride for visible light photocatalysis. Adv. Mater. 28, 6471-6477 (2016). https://doi.org/10.1002/adma.201601567

32. S. Su, Q. Han, X. Wang, J. Zhu, Synthesis of nanosheet-based hierarchical $\mathrm{BiO}_{2}$ microtubes and its photocatalytic performance. Appl. Surf. Sci. 455, 616-621 (2018). https://doi. org/10.1016/j.apsusc.2018.05.164

33. Y. Wu, L. Zhang, Y. Zhou, L. Zhang, Y. Li et al., Lightinduced $\mathrm{ZnO} / \mathrm{Ag} / \mathrm{rGO}$ bactericidal photocatalyst with synergistic effect of sustained release of silver ions and enhanced reactive oxygen species. Chin. J. Catal. 40, 691-702 (2019). https://doi.org/10.1016/S1872-2067(18)63193-6 
34. X. Chen, J. Zhang, X. Fu, M. Antonietti, X. Wang, Fe-g- $\mathrm{C}_{3} \mathrm{~N}_{4^{-}}$ catalyzed oxidation of benzene to phenol using hydrogen peroxide and visible light. J. Am. Chem. Soc. 131, 11658-11659 (2009). https://doi.org/10.1021/ja903923s

35. Y. Wu, P. Wang, X. Zhu, Q. Zhang, Z. Wang et al., Composite of $\mathrm{CH}_{3} \mathrm{NH}_{3} \mathrm{PbI}_{3}$ with reduced graphene oxide as a highly efficient and stable visible-light photocatalyst for hydrogen evolution in aqueous HI solution. Adv. Mater. 30, 1704342 (2018). https://doi.org/10.1002/adma.201704342

36. C. Dong, Z. Ma, R. Qie, X. Guo, C. Li et al., Morphology and defects regulation of carbon nitride by hydrochloric acid to boost visible light absorption and photocatalytic activity. Appl. Catal. B: Environ. 217, 629-636 (2017). https://doi. org/10.1016/j.apcatb.2017.06.028

37. J. Fu, B. Zhu, C. Jiang, B. Cheng, W. You et al., Hierarchical porous O-doped $\mathrm{g}-\mathrm{C}_{3} \mathrm{~N}_{4}$ with enhanced photocatalytic $\mathrm{CO}_{2}$ reduction activity. Small 13, 1603938 (2017). https://doi. org/10.1002/smll.201603938

38. F. Wei, Y. Liu, H. Zhao, X. Ren, J. Liu et al., Oxygen selfdoped $g-\mathrm{C}_{3} \mathrm{~N}_{4}$ with tunable electronic band structure for unprecedentedly enhanced photocatalytic performance. Nanoscale 10, 4515-4522 (2018). https://doi.org/10.1039/ C7NR09660G

39. C. Yang, Q. Jiang, W. Li, H. He, L. Yang et al., Ultrafine Pt nanoparticle-decorated 3D hybrid architectures built from reduced grapheme oxide and MXene nanosheets for methanol oxidation. Chem. Mater. 31, 9277-9287 (2019). https://doi. org/10.1021/acs.chemmater.9b02115

40. R. Zhong, Z. Zhang, S. Luo, Z.C. Zhang, L. Huang et al., Comparison of $\mathrm{TiO}_{2}$ and $\mathrm{g}-\mathrm{C}_{3} \mathrm{~N}_{4} 2 \mathrm{D} / 2 \mathrm{D}$ nanocomposites from three synthesis protocols for visible-light induced hydrogen evolution. Catal. Sci. Technol. 9, 75-85 (2019). https://doi. org/10.1039/C8CY00965A

41. V.W. Lau, I. Moudrakovski, T. Botari, S. Weinberger, M.B. Mesch et al., Rational design of carbon nitride photocatalysts by identification of cyanamide defects as catalytically relevant sites. Nature Commun. 7, 12165 (2016). https://doi. org/10.1038/ncomms 12165

42. C. Liu, H. Huang, W. Cui, F. Dong, Y. Zhang, Band structure engineering and efficient charge transport in oxygen substituted $\mathrm{g}-\mathrm{C}_{3} \mathrm{~N}_{4}$ for superior photocatalytic hydrogen evolution. Appl. Catal. B: Environ. 230, 115-124 (2018). https://doi. org/10.1016/j.apcatb.2018.02.038

43. Y. Yu, W. Yan, X. Wang, P. Li, W. Gao et al., Surface engineering for extremely enhanced charge separation and photocatalytic hydrogen evolution on $\mathrm{g}-\mathrm{C}_{3} \mathrm{~N}_{4}$. Adv. Mater. 30, 1705060 (2018). https://doi.org/10.1002/adma.201705060
44. D. Xu, B. Cheng, W. Wang, C. Jiang, J. Yu, $\mathrm{Ag}_{2} \mathrm{CrO}_{4} / g-\mathrm{C}_{3} \mathrm{~N}_{4} /$ graphene oxide ternary nanocomposite $\mathrm{Z}$-scheme photocatalyst with enhanced $\mathrm{CO}_{2}$ reduction activity. Appl. Catal. B: Environ. 231, 368-380 (2018). https://doi.org/10.1016/j.apcat b.2018.03.036

45. J. Tang, R. Guo, W. Zhou, C. Huang, W. Pan, Ball-flower like $\mathrm{NiO} / \mathrm{g}-\mathrm{C}_{3} \mathrm{~N}_{4}$ heterojunction for efficient visible light photocatalytic $\mathrm{CO}_{2}$ reduction. Appl. Catal. B: Environ. 237, 802-810 (2018). https://doi.org/10.1016/j.apcatb.2018.06.042

46. H. Li, Y. Wu, C. Li, Y. Gong, L. Niu et al., Design of Pt/t$\mathrm{ZrO}_{2} / \mathrm{g}-\mathrm{C}_{3} \mathrm{~N}_{4}$ efficient photocatalyst for the hydrogen evolution reaction. Appl. Catal. B: Environ. 251, 305-312 (2019). https ://doi.org/10.1016/j.apcatb.2019.03.079

47. D. Zeng, T. Zhou, W. Ong, M. Wu, X. Duan et al., Sub-5 $\mathrm{nm}$ ultra-fine $\mathrm{FeP}$ nanodots as efficient Co-catalysts modified porous $\mathrm{g}-\mathrm{C}_{3} \mathrm{~N}_{4}$ for precious-metal-free photocatalytic hydrogen evolution under visible light. ACS Appl. Mater. Interfaces 11, 5651-5660 (2019). https://doi.org/10.1021/acsami.8b209 58

48. Z. Guan, Y. Wu, P. Wang, Q. Zhang, Z. Wang et al., Perovskite photocatalyst $\mathrm{CsPbBr}_{3-} \mathrm{X}_{\mathrm{I}} \mathrm{X}$ with a bandgap funnel structure for $\mathrm{H}^{2}$ evolution under visible light. Appl. Catal. B: Environ. 245, 522-527 (2019). https://doi.org/10.1016/j.apcatb.2019.01.019

49. S. Zang, G. Zhang, Z. Lan, D. Zheng, X. Wang, Enhancement of photocatalytic $\mathrm{H}_{2}$ evolution on pyrene-based polymer promoted by $\mathrm{MoS}_{2}$ and visible light. Appl. Catal. B: Environ. 251, 102-111 (2019). https://doi.org/10.1016/j.apcatb.2019.03.061

50. L. Yang, L. Zeng, H. Liu, Y. Deng, Z. Zhou et al., Hierarchical microsphere of MoNi porous nanosheets as electrocatalyst and cocatalyst for hydrogen evolution reaction. Appl. Catal. B: Environ. 249, 98-105 (2019). https://doi.org/10.1016/j.apcat b.2019.02.062

51. Q. Liu, J. Shen, X. Yu, X. Yang, W. Liu et al., Unveiling the origin of boosted photocatalytic hydrogen evolution in simultaneously ( $\mathrm{S}, \mathrm{P}, \mathrm{O}$ )-codoped and exfoliated ultrathin $\mathrm{g}-\mathrm{C}_{3} \mathrm{~N}_{4}$ nanosheets. Appl. Catal. B: Environ. 248, 84-94 (2019). https ://doi.org/10.1016/j.apcatb.2019.02.020

52. X. Zhang, C. Yang, Z. Xue, C. Zhang, J. Qin et al., Spatial separation of charge carriers via heterogeneous structural defects in graphitic carbon nitride for photocatalytic hydrogen evolution. ACS Appl. Nano Mater. 3, 4428-4436 (2020). https ://doi.org/10.1021/acsanm.0c00535

53. J. Chen, X. Tao, L. Tao, H. Li, C. Li et al., Novel conjugated organic polymers as candidates for visible-light-driven photocatalytic hydrogen production. Appl. Catal. B: Environ. 241, 461-470 (2019). https://doi.org/10.1016/j.apcatb.2018.09.011 